\title{
Low accuracy of endoscopic ultrasonography for detailed T staging in gastric cancer
}

\author{
Han Hong Lee', Chul Hyun Lim², Jae Myung Park², Yu Kyung Cho², Kyo Young Song ${ }^{1}$, Hae Myung Jeon ${ }^{1}$ \\ and Cho Hyun Park ${ }^{1 *}$
}

\begin{abstract}
Background: The accuracy of endoscopic ultrasonography (EUS) for preoperative staging of gastric cancer varies. The aim of this study was to investigate the accuracy of EUS tumor ( $\mathrm{T}$ ) and node (N) staging, and to identify the histopathological factors influencing accuracy based on the detailed tumor depth of gastric cancer.

Methods: In total, 309 patients with gastric cancer with confirmed pathological staging underwent EUS examination for preoperative staging at Seoul St. Mary's Hospital, Korea, between January and December 2009. The $T$ and $N$ staging of EUS and the pathologic report were compared.

Results: The overall accuracies of EUS for T stage and the detailed T stages were $70.2 \%$ and $43.0 \%$, respectively. In detailed stage, tumors greater than $50 \mathrm{~mm}$ in diameter were significantly associated with T overstaging (odds ratio $(O R)=2.094)$. The overall accuracy of EUS for $N$ staging was $71.2 \%$. Tumor size $(20 \mathrm{~mm} \leq$ size $<50 \mathrm{~mm}, \mathrm{OR}=4.389$; and $50 \mathrm{~mm} \leq$ size, $\mathrm{OR}=8.170$ ), cross-sectional tumor location (circumferential, $\mathrm{OR}=4.381$ ) and tumor depth (submucosa, $\mathrm{OR}=3.324$; muscular propria, $\mathrm{OR}=6.923$; sub-serosa, $\mathrm{OR}=4.517$; and serosa-exposed, $\mathrm{OR}=6.495$ ) were significant factors affecting incorrect nodal detection.
\end{abstract}

Conclusions: Careful attention is required during EUS examination of large-sized gastric cancers to increase accuracy, especially for T staging.

Keywords: Cancer staging, Endoscopic ultrasonography, Stomach neoplasm

\section{Background}

Gastric cancer is the second leading cause of cancer deaths worldwide [1]. Removal of a primary tumor by perigastric lymphadenectomy is accepted as the only way to increase long-term survival in patients with gastric cancer [2]; however, the operative method and access route can vary, based on preoperative tumor stage and tumor characteristics. Compared with serosal-exposed lesions of with a tumor (T) stage of greater than T3, which can be distinguished somewhat easily, distinguishing preoperative tumor depths for gastric cancers less than T2 is crucial because it determines the operative method, including choice of endoscopic submucosal dissection (ESD), laparoscopic gastrectomy, or open gastrectomy. In addition, preoperative prediction regarding

\footnotetext{
*Correspondence: chpark@catholic.ac.kr

'Department of Surgery, Division of Gastrointestinal Surgery, College of

Medicine, The Catholic University of Korea, Seoul, South Korea

Full list of author information is available at the end of the article
}

the presence of lymph-node metastasis is a decisive factor in selecting endoscopic or surgical resection.

The development of endoscopic ultrasonography (EUS) has increased the accuracy of preoperative staging and diagnosis of upper gastrointestinal malignancies, including gastric cancer, and has had a major effect in determining the therapeutic options for gastric cancer. At present, EUS is the most valuable method for $\mathrm{T}$ staging of gastric cancer and is also used for detecting regional lymph-node involvement [3-6]; however, the accuracy of EUS for T and perigastric $\mathrm{N}$ staging varies $[6,7]$. In addition, there have been few studies assessing the accuracy rate of $\mathrm{T}$ staging with regard tothe gastric wall layers (mucosa, submucosa, muscular propria, sub-serosa, and serosa), which can be identified by EUS. Consequently, there are no guidelines regarding the clinicopathological factors requiring attention during a EUS check-up, and the accuracy rates are still undetermined.

The aim of this study was to determine the accuracy of EUS with regard to tumor depth and nodal metastasis, 
and to analyze the histopathological factors affecting the accuracy of EUS in gastric cancer, with a particular focus on the detailed gastric wall layers.

\section{Methods}

\section{Ethics approval}

The study protocol was approved by the institutional review board (KC10RISE0441).

\section{Patients}

From January to December 2009, 491 patients underwent gastric cancer surgery at Seoul St. Mary's Hospital, Seoul, Korea.We prospectively collected the clinicopathological date of 436 patients who were diagnosed with pathological cancer staging (the remaining patients comprised thirty-seven patients who could not undergo gastric resection, sixteen patients for whom preoperative cancer staging was difficult (including incomplete ESD, neoadjuvant chemotherapy, and remnant gastric cancer) and two patients with pathological non-measurable lesions). Of these 436 patients, 309 (184 men (59.5\%), 125 women (40.5\%); mean \pm SD age $57.5 \pm 12.2$ years, range 26-86 years),for whom EUS was used as a preoperative diagnostic tool, were enrolled in this retrospective study.

\section{Endoscopic ultrasonography equipment and technique}

EUS was performed with a radial transducer (12 to $20 \mathrm{MHz}$; GF-UM2000; Olympus, Tokyo, Japan), and in some cases, a $20 \mathrm{MHz}$ miniprobe (Olympus) was also used. After the stomach was filled with 300 to $600 \mathrm{~mL}$ of water, the tumor infiltration depth was evaluated based on the five-layered gastric wall structure. Assessment of tumor depth by EUS was made in accordance with the International Union Against Cancer TNM Classification (6th edition): T1a, cancer invading the mucosal layer; T1b, cancer invading the submucosal layer; T2a, cancer invading the muscularis propria; $\mathrm{T} 2 \mathrm{~b}$, cancer invading the subserosal layer; T3, cancer penetrating the serosal layer; and T4, cancer invading adjacent structures (Figure 1).
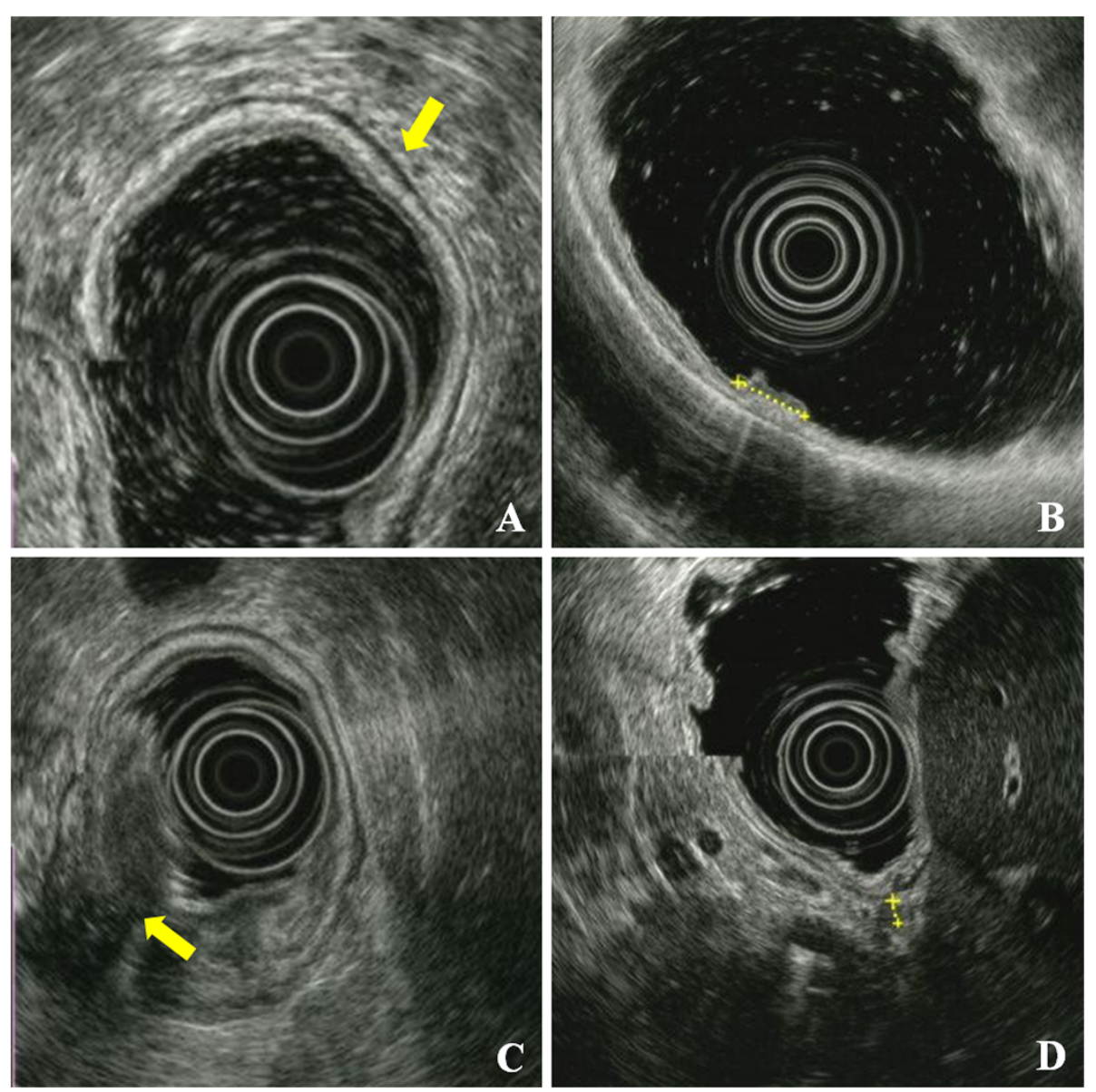

Figure 1 Endoscopic ultrasonography (EUS) (A) EUS showing normal layers of gastric wall, with the five-layered echo pattern being clearly visible (arrow). (B) EUS of early gastric cancer (T1a), showing a focal thickening area confined to layers 1 and 2(dotted line). (C) EUS image of advanced gastric cancer (T3); the tumor involves all layers and extends beyond the the outermost layer of the gastric wall (arrow). (D) EUS showing a metastatic lymph node (dotted line). 
Lymph nodes were defined by the size and shape of identified hypoechoic structures in perigastric tissues. Hypoechoic nodes larger than $5 \mathrm{~mm}$ with round and well-demarcated margins were considered positive for metastasis. A diagnosis of $\mathrm{N} 2$ stage was made when the lymph-node metastasis was $>30 \mathrm{~mm}$ from the primary lesion. Fine-needle aspiration (FNA) was not performed for lymph nodes that appeared to be metastatic.

\section{Assessment of endoscopic ultrasonography staging}

The preoperative EUS T and N staging results were compared with each pathological stage. The accuracy, overstaging, and understaging rates for EUS $\mathrm{T}$ staging were calculated using two methods: all stages (T1, T2, T3, and T4) and all detailed stages (T1a, T1b, T2a, T2b, T3, and $\mathrm{T} 4$ ). The correlations between EUS $\mathrm{T}$ overstaging and understaging and histopathological factors (including tumor size, tumor location, histological type, ulceration, and Lauren's classification,) were analyzed for the 309 cases. Tumor size was classified as less than $20 \mathrm{~mm}, 2$ to $50 \mathrm{~mm}$, or greater than $50 \mathrm{~mm}$. Tumor locations were subclassified using two criteria. One group was divided into upper, middle, and lower thirds, based on the longitudinal portions of the stomach, and the other group was divided into wall, curvature, and circumferential, sorted according to the cross-sectional portions. The histological types of gastric cancer, in accordance with the World Health Organization classification, were categorized into differentiated and undifferentiated types. Poorly differentiated tubular adenocarcinoma, signet ring cell adenocarcinoma, and mucinous adenocarcinoma belonged to the undifferentiated group. The accuracy rate for EUS $\mathrm{N}$ staging And the correlations between EUS N accuracy and histopathological factors that added to tumor depth were analyzed for the 309 cases.

\section{Statistical analysis}

Tumor characteristics and their EUS stages were analyzed using the $x^{2}$ test or Fisher's exact test for proportions. Factors with an effect on EUS TN staging were analyzed by binary multiple regression analysis. Statistical analyses were performed with SPSS software (version 13.0; SPSS, Chicago, IL, USA), and $P<0.05$ was considered significant.

\section{Results}

\section{Study groups}

Of the 309 patients, the pathological $\mathrm{T}$ staging showed that there were 107 cases of T1a (40.8\%), $85 \mathrm{~T} 1 \mathrm{~b}$ (32.4\%), 36 T2a (13.7\%), 34 T2b (13.0\%), 45 T3 (14.6\%), and 2 of T4 (0.6\%). For pathological N stage, there were 213 N0 cases, which comprised the largest proportion (68.9\%). The clinical data and pathological stage of each group are shown in Table 1.
Table 1 Patient demographics and pathological stages

\begin{tabular}{|c|c|}
\hline Variable & Result $(n=309)$ \\
\hline Age, years $^{1}$ & $57.5 \pm 12.2(26-86)$ \\
\hline \multicolumn{2}{|l|}{ Gender } \\
\hline Male & $184(59.5)$ \\
\hline Female & $125(40.5)$ \\
\hline \multicolumn{2}{|l|}{$\overline{p T}$} \\
\hline T1a & 107 (34.6) \\
\hline $\mathrm{T} 1 \mathrm{~b}$ & $85(27.5)$ \\
\hline T2a & $36(11.7)$ \\
\hline $\mathrm{T} 2 \mathrm{~b}$ & $34(11.0)$ \\
\hline $\mathrm{T} 3$ & $45(14.6)$ \\
\hline T4 & $2(0.6)$ \\
\hline \multicolumn{2}{|l|}{$\mathrm{pN}$} \\
\hline No & $213(68.9)$ \\
\hline N1 & $72(23.3)$ \\
\hline $\mathrm{N} 2$ & $11(3.6)$ \\
\hline N3 & $13(4.2)$ \\
\hline \multicolumn{2}{|l|}{$\mathrm{pM}$} \\
\hline MO & $301(97.4)$ \\
\hline M1 & $8(2.6)$ \\
\hline \multicolumn{2}{|c|}{ Sixth AJCC stage } \\
\hline la & $167(54.0)$ \\
\hline $\mathrm{lb}$ & $60(19.4)$ \\
\hline$\|$ & $38(12.3)$ \\
\hline IIIa & $22(7.1)$ \\
\hline IIlb & $6(1.9)$ \\
\hline IV & $16(5.2)$ \\
\hline
\end{tabular}

AJCC, American Joint Committee on Cancer.

${ }^{1}$ Values are means \pm standard deviation (range). All other values are $\mathrm{n}(\%)$.

\section{T staging by endoscopic ultrasonography}

In all 309 cases examined by EUS, the overall accuracy of EUS for T staging was $70.2 \%$ (217/309). The rates of overstaging and understaging were $23.6 \%(73 / 309)$ and $6.1 \%$ (19/309), respectively. In the detailed $\mathrm{T}$ staging of 309 cases, the overall accuracy rate decreased to $43.0 \%$ $(133 / 309)$, and the overstaging and understaging rates increased to $44.3 \%(137 / 309)$ and $12.6 \%$ (39/309), respectively. Two versions of the comparison of $\mathrm{T}$ stage by EUS and pathology are shown in Table 2.

$\mathrm{T}$ overstaging was correlated with tumor size $(P=0.03$ however, $\mathrm{T}$ understaging was not related to any clinicopathological factor. In multivariate analysis, a tumor size greater than $50 \mathrm{~mm}$ was a significant factor correlated with overstaging by EUS (odds ratio $(\mathrm{OR})=2.09$; 95\% confidence interval (CI) 1.13 to $3.88, P<0.02$ ) (Table 3; Table 4). Subgroup analysis was performed, and the cases were divided into two groups based on tumor depth for overstaging and understaging: early gastric cancers (EGCs; T1a, T1b) and advanced gastric cancers (AGCs; T2a, T2b, T3, T4). Tumor size was correlated 
Table 2 Accuracy of endoscopic ultrasonography (EUS) for T staging

\begin{tabular}{|c|c|c|c|c|c|c|c|c|c|c|c|c|c|}
\hline \multirow[t]{2}{*}{ EUS stage } & \multicolumn{4}{|c|}{ Pathological stage } & \multirow[b]{2}{*}{ Total } & \multirow[t]{2}{*}{ EUS stage } & \multicolumn{6}{|c|}{ Pathological stage } & \multirow[b]{2}{*}{ Tota } \\
\hline & T1 & $\mathrm{T} 2$ & T3 & T4 & & & T1a & T1b & $\mathrm{T} 2 \mathrm{a}$ & $\mathrm{T} 2 \mathrm{~b}$ & T3 & T4 & \\
\hline T1 & 155 & 9 & 3 & 0 & 174 & T1a & 34 & 11 & 0 & 0 & 0 & 0 & 46 \\
\hline $\mathrm{T} 2$ & 36 & 37 & 5 & 0 & 87 & $\mathrm{~T} 1 \mathrm{~b}$ & 60 & 50 & 6 & 3 & 3 & 0 & 128 \\
\hline $\mathrm{T3}$ & 1 & 22 & 25 & 2 & 45 & T2a & 11 & 21 & 16 & 9 & 2 & 0 & 64 \\
\hline \multirow[t]{3}{*}{$\mathrm{T4}$} & 0 & 2 & 12 & 0 & 3 & $\mathrm{~T} 2 \mathrm{~b}$ & 2 & 2 & 4 & 8 & 3 & 0 & 23 \\
\hline & & & & & & T3 & 0 & 1 & 9 & 13 & 25 & 2 & 45 \\
\hline & & & & & & T4 & 0 & 0 & 1 & 1 & 12 & 0 & 3 \\
\hline Total & 192 & 70 & 45 & 2 & 309 & Total & 107 & 85 & 36 & 34 & 45 & 2 & 309 \\
\hline Overall accuracy, \% & & & 70.2 & & & & & & & 43.0 & & & \\
\hline Overall accuracy, $\%{ }^{1}$ & & & - & & & & & & & 41.2 & & & \\
\hline
\end{tabular}

'pT1a-pT2b; $n=262$.

with EUS overstaging in both subgroups $(P=0.03, P<$ 0.001 , respectively), and cross-sectional tumor location $(P=0.04)$ was associated with overstaging in the AGC group. In multivariate analysis for subgroup, a tumor size greater than $50 \mathrm{~mm}$ was also a factor affecting EUS overstaging in the EGC (OR $=3.00,95 \% \mathrm{CI}, 1.19$ to $7.56 ; P=0.02)$ and $\mathrm{AGC}(\mathrm{OR}=5.40 ; 95 \% \mathrm{CI}, 2.26$

Table 3 Histopathological factors affecting endoscopic ultrasonography (EUS) T staging

\begin{tabular}{|c|c|c|c|c|c|}
\hline Variables & $n$ & $\begin{array}{c}\text { Overstaging, } \\
\%\end{array}$ & $P$ & $\begin{array}{c}\text { Understaging, } \\
\%\end{array}$ & $P$ \\
\hline Total & 309 & $137(44.3)$ & & 39 (12.6) & \\
\hline \multicolumn{6}{|l|}{ Tumor size, mm } \\
\hline$<20$ & 80 & $30(37.5)$ & 0.03 & $7(8.8)$ & 0.42 \\
\hline $2-50$ & 141 & $58(41.1)$ & & $21(14.9)$ & \\
\hline$\geq 50$ & 88 & $49(55.7)$ & & $11(12.5)$ & \\
\hline \multicolumn{6}{|l|}{ Tumor locationl } \\
\hline Upper & 18 & $6(33.3)$ & 0.62 & $3(16.7)$ & 0.28 \\
\hline Middle & 137 & $61(44.5)$ & & $21(15.3)$ & \\
\hline Lower & 154 & $70(45.5)$ & & $15(9.7)$ & \\
\hline \multicolumn{6}{|l|}{ Tumor locationll } \\
\hline Wall & 162 & $70(43.2)$ & 0.32 & $20(12.3)$ & 0.65 \\
\hline Curvature & 131 & $57(43.5)$ & & $16(12.2)$ & \\
\hline Circumferential & 16 & $10(62.5)$ & & $3(18.8)$ & \\
\hline \multicolumn{6}{|l|}{ Histological type } \\
\hline Differentiated & 147 & $66(44.9)$ & 0.85 & $21(14.3)$ & 0.40 \\
\hline Undifferentiated & 162 & $71(43.8)$ & & $18(11.1)$ & \\
\hline \multicolumn{6}{|l|}{ Ulceration } \\
\hline Yes & 227 & $94(41.4)$ & 0.08 & 31 (13.7) & 0.36 \\
\hline No & 82 & $43(52.4)$ & & $8(9.8)$ & \\
\hline \multicolumn{6}{|l|}{ Lauren } \\
\hline Intestinal type & 142 & $63(44.4)$ & 0.88 & $16(11.3)$ & 0.15 \\
\hline Mixed type & 60 & $25(41.7)$ & & $12(20.0)$ & \\
\hline Diffuse type & 107 & 49 (45.8) & & $11(10.3)$ & \\
\hline
\end{tabular}

to $12.91 ; P<0.01$ ) subgroups (Table 4 ; Table 5 ). No factors were significantly associated with understaging in subgroup analysis (data not shown).

\section{$\mathrm{N}$ staging by endoscopic ultrasonography}

The comparative results of $\mathrm{N}$ staging by EUS and the pathological reports are shown in Table 6 . The $\mathrm{N}$ staging accuracy in the 309 patients was $71.2 \%$. Incorrect nodal staging by EUS was correlated with tumor size $(P<0.001)$, cross-sectional tumor location $(P<0.001)$, and tumor depth $(P<0.001)$, and these three factors were significantly associated with inaccurate nodal staging on multivariate analysis. Tumor size greater than $50 \mathrm{~mm}$ was the strongest factor for inaccurate EUS nodal staging (OR $=8.170$, 95\% CI 2.47 to $27.05, P=0.001$ ), and a tumor size greater than $20 \mathrm{~mm}$ was also a significant factor $(\mathrm{OR}=4.389,95 \% \mathrm{CI}$ 1.45 to $13.31, P<0.010)$. Circumferential location was identified as a significant factor (OR $=4.38,95 \%$ CI 1.02 to $18.83, P<0.05)$, and all tumor depths over the mucosal layer were significant factors for inaccurate nodal staging (submucosa, $\mathrm{OR}=3.324,95 \% \mathrm{CI} 1.35$ to $8.20, P<0.01$, muscular propria, $\mathrm{OR}=6.92,95 \%$ CI 2.52 to $19.03, P<$ 0.001, sub-serosa, $\mathrm{OR}=4.52,95 \%$ CI 1.57to12.10, $P<0.01$, serosa-exposed, $\mathrm{OR}=6.50,95 \% \mathrm{CI} 2.28$ to $18.51, P<0.001$ ) (Table 7).

Table 4 Multivariate analysis of histopathological factors affecting EUS $T$ staging

\begin{tabular}{lccc}
\hline Variable & $\boldsymbol{P}$ & Odds Ratio & $\mathbf{9 5 \%} \mathrm{Cl}$ \\
\hline Overstaging & \multicolumn{3}{l}{} \\
\hline Tumor size $\geq 50 \mathrm{~mm}$ & 0.020 & 2.09 & 1.13 to 3.88 \\
\hline EGC overstaging & & & \\
\hline Tumor size $\geq 50 \mathrm{~mm}$ & 0.02 & 3.00 & 1.19 to 7.56 \\
\hline AGC overstaging & & & \\
\hline Tumor size $\geq 50 \mathrm{~mm}$ & $<0.001$ & 5.40 & 2.26 to 12.91
\end{tabular}

AGC, advanced gastric cancer; $\mathrm{Cl}$, confidence interval; $\mathrm{EGC}$, early gastric cancer; EUS, endoscopic ultrasonography. 


\section{Discussion}

The accuracy of EUS for gastric cancer varies. In previous studies, EUS has had an accuracy of $65 \%$ to $92 \%$ for T staging, and $50 \%$ to $90 \%$ for $\mathrm{N}$ staging [6-13]. In most studies, $\mathrm{T}$ stage has been classified as T1, T2, T3, or T4, instead of T1a, T1b, T2a, T2b, T3, and T4 [3-5,9-27]. A few studies have estimated the accuracy of detailed T staging by EUS, but they were limited to distinguishing the mucosa from the submucosal layer [8,28-30]. In the present study, we found the overall accuracy of EUS for T staging was $70.2 \%$, which was similar to previous studies. However, when $\mathrm{T}$ stage was subdivided into the detailed stages, the overall accuracy rate for $\mathrm{T}$ staging was only $43.0 \%$, and the overstaging rate increased sharply to $44.3 \%$. These unexpected results were mainly the result of overstaging of mucosal lesions into submucosal lesions, and occurred in 60 cases.

EUS images of the normal gastric wall show a fivelayered structure. Gastric cancer invading the serosa can be adequately diagnosed by traditional endoscopy and computed tomography (CT). EUS tends to overestimate the $\mathrm{T}$ stage because of the difficulty in distinguishing
Table 6 Accuracy of endoscopic ultrasonography (EUS) for $\mathbf{N}$ staging EUS stage Pathological stage

\begin{tabular}{lrrrrr} 
& \multicolumn{1}{c}{ N0 } & N1 & N2 & N3 & Total \\
\hline N0 & 190 & 44 & 1 & 1 & 236 \\
\hline N1 & 22 & 27 & 7 & 10 & 66 \\
\hline N2 & 1 & 1 & 3 & 2 & 7 \\
\hline Total & 213 & 72 & 11 & 13 & 309 \\
\hline
\end{tabular}

Overall accuracy, \% 71.2

invasion through the subserosal fat (T2b) and the serosa (T3), which is very thin in some areas [22]. EUS findings for gastric cancer at less than stage T2 can profoundly affect selection of operative method, unlike stages more severe than T3, for which the treatment plan involves open gastrectomy. The treatment algorithm based on the detailed T stage by EUS is described in Figure 2. In our population of 262 cases limited to T2b, the overall accuracy rate decreased to $41.2 \%$, and the overstaging rate increased to $47.7 \%$. Therefore, we attempted to identify the factor(s) affecting the overstaging of depth,

Table 5 Histopathological factors affecting $\mathbf{T}$ overstaging in the subgroups

\begin{tabular}{|c|c|c|c|c|c|c|}
\hline \multirow[t]{2}{*}{ Variables } & \multicolumn{3}{|c|}{ EGCs } & \multicolumn{3}{|c|}{ AGCs } \\
\hline & $n$ & Overstaging, n (\%) & $P$ & $n$ & Overstaging, n (\%) & $P$ \\
\hline Total & 192 & $97(50.5)$ & & 117 & $40(34.2)$ & \\
\hline \multicolumn{7}{|l|}{ Tumor size, mm } \\
\hline$<20$ & 75 & $30(40.0)$ & 0.03 & & & \\
\hline 2to50 & 90 & $49(54.4)$ & & 56 & $9(16.1)^{1}$ & $<0.001$ \\
\hline$\geq 50$ & 27 & $18(66.7)$ & & 61 & $31(50.8)$ & \\
\hline \multicolumn{7}{|l|}{ Tumor locationl } \\
\hline Upper & 3 & $1(33.3)$ & 0.87 & 15 & $5(33.3)$ & \\
\hline Middle & 81 & $42(51.9)$ & & 56 & 19 (33.9) & 0.99 \\
\hline Lower & 108 & $54(50.0)$ & & 46 & $16(34.8)$ & \\
\hline \multicolumn{7}{|l|}{ Tumor locationll } \\
\hline Wall & 115 & 57 (49.6) & 0.88 & 47 & $13(27.7)$ & \\
\hline Curvature & 75 & $39(52.0)$ & & 56 & $18(32.1)$ & \\
\hline Circumferential & 2 & $1(50.0)$ & & 14 & $9(64.3)$ & 0.04 \\
\hline \multicolumn{7}{|l|}{ Histological type } \\
\hline Differentiated & 102 & $47(46.1)$ & 0.19 & 45 & $19(42.2)$ & 0.15 \\
\hline Undifferentiated & 90 & $50(55.6)$ & & 72 & $21(29.2)$ & \\
\hline \multicolumn{7}{|l|}{ Ulceration } \\
\hline Yes & 139 & $68(48.9)$ & 0.47 & 88 & $26(29.5)$ & 0.07 \\
\hline No & 53 & $29(54.7)$ & & 29 & $14(48.3)$ & \\
\hline \multicolumn{7}{|l|}{ Lauren } \\
\hline Intestinal type & 101 & $46(45.5)$ & 0.33 & 41 & $17(41.5)$ & 0.32 \\
\hline Mixed type & 31 & $18(58.1)$ & & 29 & $7(24.1)$ & \\
\hline Diffuse type & 60 & $33(55.0)$ & & 47 & $16(34.0)$ & \\
\hline
\end{tabular}


Table 7 Histopathological factors affecting endoscopic ultrasonography (EUS) $\mathbf{N}$ staging

\begin{tabular}{|c|c|c|c|c|c|}
\hline Variables & $n$ & Incorrect staging, n (\%) & $P$ & Odds ratio $(95 \% \mathrm{Cl})$ & $P$ \\
\hline Total & 309 & $90(29.1)$ & & & \\
\hline \multicolumn{6}{|l|}{ Tumor size, mm } \\
\hline$<20 \mathrm{~mm}$ & 80 & $4(5.0)$ & $<0.001$ & 4.389 (1.447to13.307) & $<0.01$ \\
\hline 2 to $50 \mathrm{~mm}$ & 141 & $38(27.0)$ & & 8.170 (2.468to27.050) & 0.001 \\
\hline$\geq 50 \mathrm{~mm}$ & 88 & $48(54.5)$ & & & \\
\hline \multicolumn{6}{|l|}{ Tumor location I } \\
\hline Upper & 18 & $9(50.0)$ & 0.13 & & \\
\hline Middle & 137 & $38(27.7)$ & & & \\
\hline Lower & 154 & $43(27.9)$ & & & \\
\hline \multicolumn{6}{|l|}{ Tumor location II } \\
\hline Wall & 162 & $38(23.5)$ & $<0.001$ & 1.00 (0.55to 1.82$)$ & 0.10 \\
\hline Curvature & 131 & 39 (29.8) & & 4.38 (1.02to18.83) & 0.05 \\
\hline Circumferential & 16 & $13(81.3)$ & & & \\
\hline \multicolumn{6}{|l|}{ Histological type } \\
\hline Differentiated & 147 & $41(27.9)$ & 0.65 & & \\
\hline Undifferentiated & 162 & $49(30.2)$ & & & \\
\hline \multicolumn{6}{|l|}{ Ulceration } \\
\hline Yes & 227 & $63(27.8)$ & 0.38 & & \\
\hline No & 82 & $27(32.9)$ & & & \\
\hline \multicolumn{6}{|l|}{ Lauren } \\
\hline Intestinal type & 142 & $38(26.8)$ & 0.23 & & \\
\hline Mixed type & 60 & $23(38.3)$ & & & \\
\hline Diffuse type & 107 & $29(27.1)$ & & & \\
\hline \multicolumn{6}{|l|}{ Tumor depth } \\
\hline Mucosa & 107 & $8(7.5)$ & & 3.32 (1.35to8.20) & $<0.01$ \\
\hline Sub-mucosa & 85 & 22 (25.9) & & $6.92(2.52$ to 19.03$)$ & $<0.001$ \\
\hline Muscular propria & 36 & $16(44.4)$ & & $4.52(1.57$ to 12.10$)$ & $<0.01$ \\
\hline Sub-serosa & 34 & $15(44.1)$ & & 6.49 (2.28to18.51) & $<0.001$ \\
\hline Serosa-exposed & 47 & $29(61.7)$ & $<0.001$ & & \\
\hline
\end{tabular}

$\mathrm{Cl}$, confidence interval.

and subsequently evaluated the factors in subgroups as EGCs and AGCs.

Our results showed that the rate of overstaging tended to increase with increasing tumor size, and a tumor size greater than $50 \mathrm{~mm}$ was a significant factor affecting EUS overstaging. However, the proportion of EGCs $(97 / 137 ; 70.8 \%)$ was greater than that of AGCs $(40 / 137 ; 29.2 \%)$ in cases with overstaging. We performed subgroup analysis to determine whether tumor size, identified as an influencing factor for $\mathrm{T}$ overstaging, would work in the same way in both groups with very different proportions. Large tumor size was associated with $\mathrm{T}$ overstaging in univariate analysis of both groups, and a tumor size greater than $50 \mathrm{~mm}$ was significantly associated. Kim et al. [31] reported that tumors larger than $30 \mathrm{~mm}$ could cause EUS overstaging. In their study, in which the T1 stage was subdivided into $\mathrm{T} 1 \mathrm{a}$ and $\mathrm{T} 1 \mathrm{~b}$, but $\mathrm{T} 2$ stage was not subdivided, the overall T staging accuracy rate was $71.8 \%$. Of our 309 cases, 171 (55.3\%) had tumors larger than $30 \mathrm{~mm}$, with $39 \%(75 / 192)$ were larger than $30 \mathrm{~mm}$ in the EGC group. As our results showed a correlation between tumor size and $\mathrm{T}$ overstaging, we considered that many tumors greater than $30 \mathrm{~mm}$ in size resulted in the low accuracy rate.

Compared with the overall accuracy rate for $\mathrm{N}$ staging which was $71.2 \%$, the accuracy rate of the 262 cases with tumor location below the sub-serosa was $76.7 \%$. In contrast to $\mathrm{T}$ staging accuracy, the accuracy of $\mathrm{N}$ staging increased when we excluded AGCs more severe than T3. This result suggested that tumor depth might influence perigastric nodal detection by EUS, and tumor depth was added as a histopathological factor possibly associated with $\mathrm{N}$ staging accuracy. Our results showed that as tumor invasion became deeper, incorrect nodal detection increased as expected, and large-sized tumors 


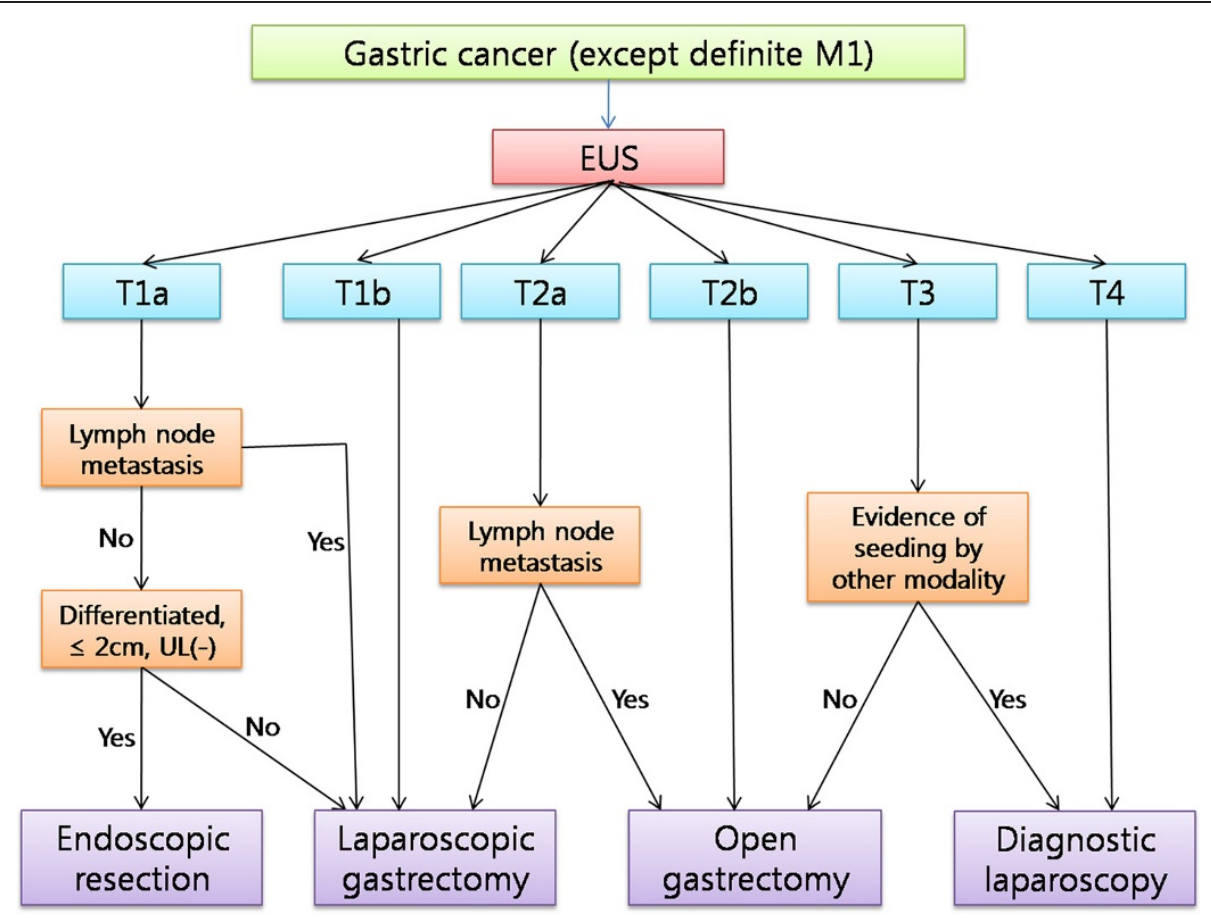

Figure 2 Treatment algorithm for gastric cancer based on the detailed tumor (T) stages. EUS, endoscopic ultrasonography; UL, ulceration.

were also associated with incorrect EUS nodal staging. The proportion of incorrect nodal staging increased equally to $44 \%$ in both the muscular propria and subserosal layers, and these layers (AGC) had higher ORs than the submucosal layer (EGC). T overstaging was correlated with a tumor size greater than $50 \mathrm{~mm}$, whereas incorrect $\mathrm{N}$ staging was significantly associated with tumors greater than $20 \mathrm{~mm}$. ESD is currently performed for differentiated, intramucosal lesions of less than $20 \mathrm{~mm}$ in diameter without ulcerations, because a tumor size greater than $30 \mathrm{~mm}$, ulcer formation, and lymphatic/ vascular involvement are regarded as independent risk factors for lymph-node metastasis in intramucosal cancer $[32,33]$. However, the expanded ESD criteria include lesions greater than $20 \mathrm{~mm}$ in diameter, ulcerative lesions, and minute submucosal cancer. Judging from our results, careful examination of nodal metastases in preoperative EUS staging and cooperative staging with another method, such as CT, is essential for determining the treatment plan for EGC lesions greater than $20 \mathrm{~mm}$ in diameter.

Although there was no statistical significance in multivariate analysis, circumferential tumor location was associated with $\mathrm{T}$ overstaging of AGCs in subgroup analysis $(P=0.04)$. In addition, this location was a significant factor determining incorrect nodal staging of EUS $(P=0.05)$. A tumor must have a broad surface to occupy a circumferential location within the stomach; therefore, the borderline significance of this particular location was considered as a secondary effect caused by the large size of the tumor.

There are some limitations to our study. First, the examiners who performed the EUS all belong to a single institution. Although many cases were enrolled in our study, the results may be just a reflection of the preference of a single institution. However, all examiners are endoscopic specialists of the upper gastrointestinal tract, and perform more than 100 cases of EUS every year. The second limitation is the definition of EUS $\mathrm{N}$ staging. EUS $\mathrm{N}$ staging of this study includes the concept of distance and is similar to the nodal staging of Japanese Gastric Cancer Association which is based on the location of metastatic lymph nodes. Because the $\mathrm{N}$ staging International Union Against Cancer TNM Classification (6th edition), which was used for pathologic nodal staging in this study, is based on the number of metastatic lymph nodes, the comparison of EUS $\mathrm{N}$ staging with pathologic $\mathrm{N}$ staging might be inappropriate. Additionally, there is no criterion for N3 staging using EUS.

However, based on our results, we suggest that extra attention should be paid not only to preoperative EUS $\mathrm{T}$ staging but to $\mathrm{N}$ staging for large-sized EGCs. In addition, because tumors larger than $50 \mathrm{~mm}$, in which the possibility of $\mathrm{T}$ overstaging is high, are mostly affiliated with AGCs, and the accuracy of nodal staging tends to decrease with increasing tumor depth, the efficacy of routine preoperative EUS for AGCs should be evaluated. Reddy et al. [34] reported that more than half 
of their survey respondents did not believe in the clinical efficacy of EUS for managing patients with gastric cancer. They also reported a trend toward underutilization of EUS when staging gastric cancer, which was unaffected by the availability of EUS in practice. At present, there are no guidelines for indicating EUS examination. EUS guidelines must be established to increase the accuracy of EUS and expand its use.

\section{Conclusions}

The accuracy of $\mathrm{T}$ staging by EUS appeared to decrease with detailed $\mathrm{T}$ staging. $\mathrm{T}$ overstaging, which caused decreased accuracy, was correlated with lesions greater than $50 \mathrm{~mm}$, and incorrect EUS nodal staging was associated with larger tumor size and deeper tumor infiltration. Consequently, careful EUS examination in association with other diagnostic tools must precede treatment planning for gastric cancer with these characteristics. Improvement in EUS equipment and techniques will be essential to overcome the weak points of the method, and an implementation guideline should be developed for improvement of the clinical efficacy of EUS.

\section{Competing interests}

The authors have no conflicts of interest or financial ties to disclose.

\section{Authors' contributions}

$\mathrm{HHL}$ and CHP were involved in the conception and design of the study, carried out data analysis, and drafted the manuscript. CHL, JMP and YKC were responsible for acquisition and interpretation of data.KYS, and HMJ were responsible for interpretation of data and CHP, KYS and HMJ carried out critical revision of the manuscript. All authors have read and approved the final manuscript.

\section{Author details}

'Department of Surgery, Division of Gastrointestinal Surgery, College of Medicine, The Catholic University of Korea, Seoul, South Korea. ${ }^{2}$ Department of Internal Medicine, College of Medicine, The Catholic University of Korea, Seoul, South Korea.

Received: 7 June 2011 Accepted: 14 October 2011

Published: 15 September 2012

\section{References}

1. Neugut Al, Hayek M, Howe G: Epidemiology of gastric cancer. Semin Oncol 1996, 23:281-291.

2. Martin RC 2nd, Jaques DP, Brennan MF, Karpeh M: Achieving RO resection for locally advanced gastric cancer: is it worth the risk of multiorgan resection? J Am Coll Surg 2002, 194:568-577.

3. Willis S, Truong S, Gribnitz S, Fass J, Schumpelick V: Endoscopic ultrasonography in the preoperative staging of gastric cancer: accuracy and impact on surgical therapy. Surg Endosc 2000, 14:951-954.

4. Bentrem D, Gerdes H, Tang L, Brennan M, Coit D: Clinical correlation of endoscopic ultrasonography with pathologic stage and outcome in patients undergoing curative resection for gastric cancer. Ann Surg Oncol 2007, 14:1853-1859.

5. Akahoshi K, Chijiiwa Y, Sasaki I, Hamada S, Iwakiri Y, Nawata H, Kabemura T: Pre-operative TN staging of gastric cancer using a $15 \mathrm{MHz}$ ultrasound miniprobe. Br J Radiol 1997, 70:703-707.

6. Kwee RM, Kwee TC: Imaging in local staging of gastric cancer: a systematic review. J Clin Oncol 2007, 25:2107-2116.

7. Tsendsuren T, Jun SM, Mian XH: Usefulness of endoscopic ultrasonography in preoperative TNM staging of gastric cancer. World J Gastroenterol 2006, 12:43-47.
8. Yanai H, Matsumoto Y, Harada T, Nishiaki M, Tokiyama H, Shigemitsu T, Tada M, Okita K: Endoscopic ultrasonography and endoscopy for staging depth of invasion in early gastric cancer: a pilot study. Gastrointest Endosc 1997, 46:212-216.

9. Botet JF, Lightdale CJ, Zauber AG, Gerdes H, Winawer SJ, Urmacher C, Brennan MF: Preoperative staging of gastric cancer: comparison of endoscopic US and dynamic CT. Radiology 1991, 181:426-432.

10. Akahoshi K, Misawa T, Fujishima H, Chijiiwa Y, Maruoka A, Ohkubo A, Nawata $\mathrm{H}$ : Preoperative evaluation of gastric cancer by endoscopic ultrasound. Gut 1991, 32:479-482.

11. Habermann CR, Weiss F, Riecken R, Honarpisheh H, Bohnacker S, Staedtler C, Dieckmann C, Schoder V, Adam G: Preoperative staging of gastric adenocarcinoma: comparison of helical CT and endoscopic US. Radiology 2004, 230:465-471.

12. Hunerbein M, Dohmoto M, Rau B, Schlag PM: Endosonography and endosonography-guided biopsy of upper-Gl-tract tumors using a curved-array echoendoscope. Surg Endosc 1996, 10:1205-1209.

13. Caletti G, Ferrari A, Brocchi E, Barbara L: Accuracy of endoscopic ultrasonography in the diagnosis and staging of gastric cancer and lymphoma. Surgery 1993, 113:14-27.

14. Ganpathi IS, So JB, Ho KY: Endoscopic ultrasonography for gastric cancer: does it influence treatment? Surg EndosC 2006, 20:559-562.

15. Bhandari S, Shim CS, Kim JH, Jung IS, Cho JY, Lee JS, Lee MS, Kim BS: Usefulness of three-dimensional, multidetector row CT (virtual gastroscopy and multiplanar reconstruction) in the evaluation of gastric cancer: a comparison with conventional endoscopy, EUS, and histopathology. Gastrointest Endosc 2004, 59:619-626.

16. Javaid G, Shah OJ, Dar MA, Shah P, Wani NA, Zargar SA: Role of endoscopic ultrasonography in preoperative staging of gastric carcinoma. ANZ J Surg 2004, 74:108-111.

17. Xi WD, Zhao C, Ren GS: Endoscopic ultrasonography in preoperative staging of gastric cancer: determination of tumor invasion depth, nodal involvement and surgical resectability. World J Gastroenterol 2003, 9:254-257.

18. Chen $\mathrm{CH}$, Yang CC, Yeh $\mathrm{YH}$ : Preoperative staging of gastric cancer by endoscopic ultrasound: the prognostic usefulness of ascites detected by endoscopic ultrasound. J Clin Gastroenterol 2002, 35:321-327.

19. Tseng $L$, Mo LR, Tio TL, Fresner YT, Jao N, Lin RC, Kuo JY, Chang KK, Wang $\mathrm{CH}$, Wey KC: Video-endoscopic ultrasonography in staging gastric carcinoma. Hepatogastroenterology 2000, 47:897-900.

20. Hunerbein M, Ghadimi BM, Haensch W, Schlag PM: Transendoscopic ultrasound of esophageal and gastric cancer using miniaturized ultrasound catheter probes. Gastrointest Endosc 1998, 48:371-375.

21. Massari M, Cioffi U, De Simone M, Bonavina L, D'Elia A, Rosso L, Ferro C, Montorsi M: Endoscopic ultrasonography for preoperative staging of gastric carcinoma. Hepatogastroenterology 1996, 43:542-546.

22. Smith JW, Brennan MF, Botet JF, Gerdes H, Lightdale CJ: Preoperative endoscopic ultrasound can predict the risk of recurrence after operation for gastric carcinoma. J Clin Oncol 1993, 11:2380-2385.

23. Ziegler K, Sanft C, Zimmer T, Zeitz M, Felsenberg D, Stein H, Germer C, Deutschmann C, Riecken EO: Comparison of computed tomography, endosonography, and intraoperative assessment in TN staging of gastric carcinoma. Gut 1993, 34:604-610.

24. Grimm H, Binmoeller KF, Hamper K, Koch J, Henne-Bruns D, Soehendra N: Endosonography for preoperative locoregional staging of esophageal and gastric cancer. Endoscopy 1993, 25:224-230.

25. Dittler HJ, Siewert JR: Role of endoscopic ultrasonography in gastric carcinoma. Endoscopy 1993, 25:162-166.

26. Francois E, Peroux J, Mouroux J, Chazalle M, Hastier P, Ferrero J, Simon J, Bourry J: Preoperative endosonographic staging of cancer of the cardia. Abdom Imaging 1996, 21:483-487.

27. Meining A, Dittler HJ, Wolf A, Lorenz R, Schusdziarra V, Siewert JR, Classen M, Hofler H, Rosch T: You get what you expect? A critical appraisal of imaging methodology in endosonographic cancer staging. Gut 2002, 50:599-603.

28. Yanai H, Noguchi T, Mizumachi S, Tokiyama H, Nakamura H, Tada M, Okita K A blind comparison of the effectiveness of endoscopic ultrasonography and endoscopy in staging early gastric cancer. Gut 1999, 44:361-365.

29. Hizawa K, Iwai K, Esaki M, Matsumoto T, Suekane H, lida M: Is endoscopic ultrasonography indispensable in assessing the appropriateness of endoscopic resection for gastric cancer? Endoscopy 2002, 34:973-978. 
30. Shimoyama S, Yasuda H, Hashimoto M, Tatsutomi Y, Aoki F, Mafune K, Kaminishi M: Accuracy of linear-array EUS for preoperative staging of gastric cardia cancer. Gastrointest Endosc 2004, 60:50-55.

31. Kim JH, Song KS, Youn YH, Lee YC, Cheon JH, Song SY, Chung JB: Clinicopathologic factors influence accurate endosonographic assessment for early gastric cancer. Gastrointest Endosc 2007, 66:901-908.

32. Gotoda T, Yamamoto H, Soetikno RM: Endoscopic submucosal dissection of early gastric cancer. J Gastroenterol 2006, 41:929-942.

33. Gotoda T, Yanagisawa A, Sasako M, Ono H, Nakanishi Y, Shimoda T, Kato Y: Incidence of lymph node metastasis from early gastric cancer: estimation with a large number of cases at two large centers. Gastric Cancer 2000, 3:219-225.

34. Reddy NK, Markowitz AB, Abbruzzese JL, Bhutani MS: Knowledge of indications and utilization of EUS: a survey of oncologists in the United States. J Clin Gastroenterol 2008, 42:892-896.

doi:10.1186/1477-7819-10-190

Cite this article as: Lee et al:: Low accuracy of endoscopic

ultrasonography for detailed T staging in gastric cancer. World Journal of Surgical Oncology 2012 10:190.

\section{Submit your next manuscript to BioMed Central and take full advantage of:}

- Convenient online submission

- Thorough peer review

- No space constraints or color figure charges

- Immediate publication on acceptance

- Inclusion in PubMed, CAS, Scopus and Google Scholar

- Research which is freely available for redistribution 